\title{
5
}

\section{CHONDRULES AS}

\section{CONDENSATION PRODUCTS}

\author{
J. A. WOOD and H. Y. MCSWEEN, JR.
}

The formation of meteoritic chondrules via condensation from the primordial solar nebula is discussed. Chondrule formation in regions where the gas/dust ratio was enhanced, and where transient high energy events heated the gas and temporarily vaporized the dust, is advocated. The observed diversity of chondrule types can be understood as resulting from local variations in the initial gas/dust proportions and other parameters.

Chondritic meteorites are characterized by the presence of small stony spheroids termed chondrules (Figure 1). The internal texture and mineralogy of chondrules indicate that they were formed as discrete dispersed objects at high temperatures $\left(>1500^{\circ} \mathrm{K}\right)$, after which they cooled relatively rapid $1 y$. Subsequent $1 y$ they agglomerated, together with material of smaller grain size and lower-temperature mineralogy, to form the parent planets of the chondritic meteorites. Many chondrites contain chondrules in great ahundance (up to $70 \%$ by volume), which makes it seem likely that some very pervasive process in the early solar system wrought them. The question of their origin has been asked repeatedly, and a number of answers have been proposed.

That the chondrules might have heen inherited intact from the pre-solar system interstellar medium has not been advocated. Chondrules are quite variable in composition, texture, and dimension, and the several chondrite subclasses contain characteristically different populations of these objects. It is unlikely that these discrete populations could have remained unmixed during formation of the solar nebula; instead it appears that the chondrules were formed by relatively local events or processes in the early solar system, then accreted promptly into chondritic aggregations.

Currently, the most widely accepted explanation for chondrules is that they are melt-droplets splashed from high-energy impacts between objects orbiting in the early solar system. The impacts may have occurred between small objects in space (Whipple 1972, Wasson 1972, Cameron 1973, Kieffer 1975, Lange and Larimer 1975), or small objects may have impacted planetary surfaces (Urey 1967, Kurat 1967, Wlotzka 1969, Dodd 1971, King et al. 1972, Fredriksson et al. 1973).

Another possibility is that the chondrules condensed in the primordial solar nebula, either during monotonic cooling of the nebula after collapse from an interstellar gas and dust cloud (Suess 1949, Wood 1962) or following hypothetical transient high-energy events in the nebula (Wood 1963, 1967). Blander and Katz (1967) have proposed condensation as metastable liquid droplets from supercooled gases. Podolak and Cameron (1974) suggest condensation in the atmosphere of the Jupiter protoplanet. 


\section{WOOD AND MCSWEEN}
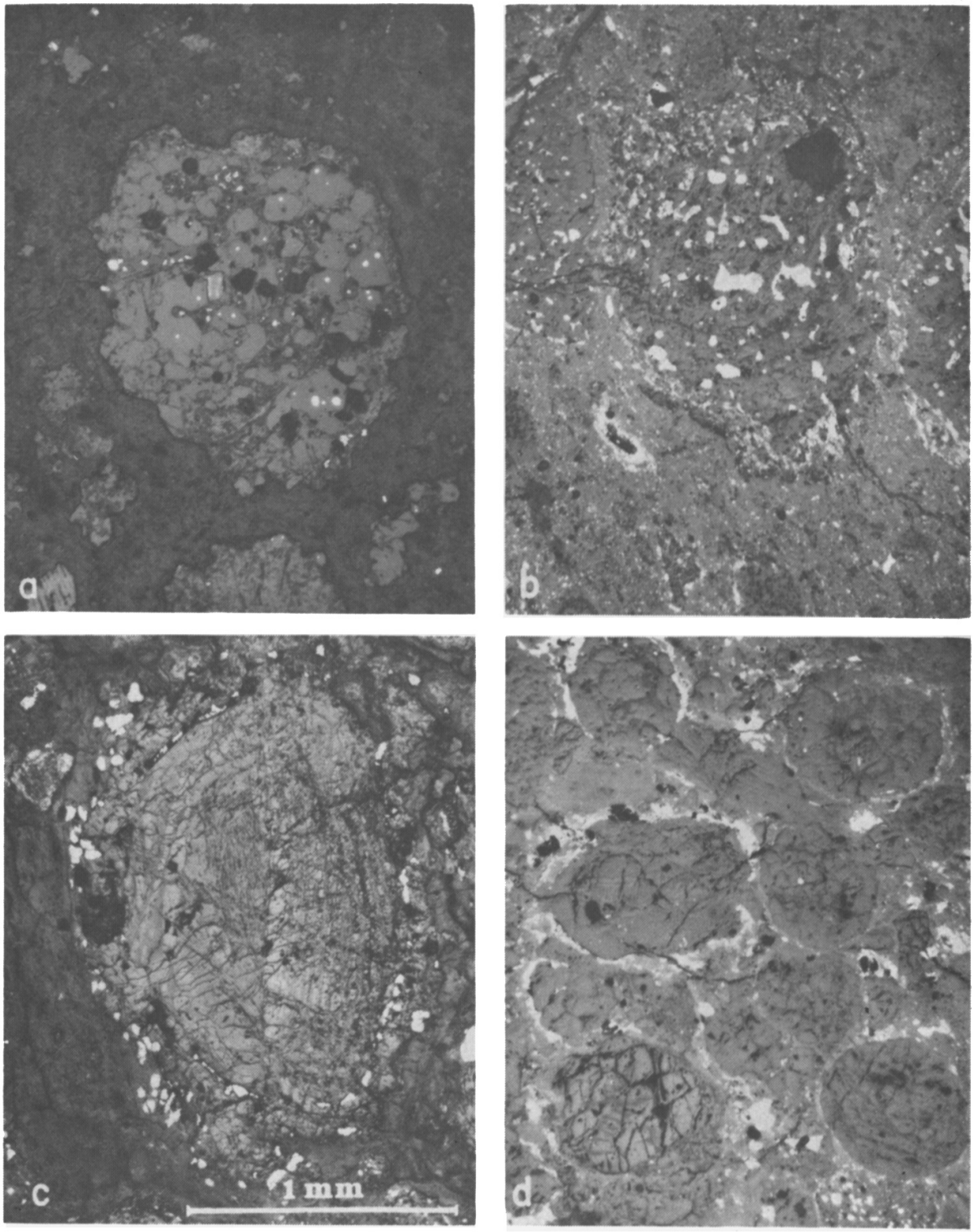

Figure 1. Photomicrographs of chondrules types, illuminated by reflected light. Scale bar in $\underline{c}$ applies to $\underline{b}, \underline{c}$, and $\underline{d}$; $a$ is four times more great $y$ magnified. Gray areas, silicate minerals; white, grains of $\mathrm{Ni}, \mathrm{Fe}$ metal, troilite (FeS) or magnetite $\left(\mathrm{Fe}_{3} \mathrm{O}_{4}\right)$; black, pits in the surface of the polished sections. a: Porous agqregates of olivine crystals (class 1) in the Murray C2 chondrite. $b$ : Irregular chondrule with dispersed troilite (class 2) in the Grosnaja C3 chondrite. c: Irregular chondrule with metal concentrated near the surface (class 3) in the Renazo c2 chondrite. d: Rounded metal-free chondrultes, som with txterior coatings of troilite, in the Krymka unequilibrated ordinal chondrite (Wlasses 5, 6). 
One other recent concept is that the remelting of dust aggregations in the nebula by electrical discharges ( 1 ightning) produced the chondrules (Whipple 1966, Cameron 1966).

A serious obsiacle to inderstanding these enigmatic ohjects has heen a tendency to oversimplify their nature, i.e., to see all of them as quenched droplets of silicate melt. Some chondrules are of this character, but many are not. The senior author has been as guilty of this oversimplification as anyone.

The small, discrete, high-temperature objects that stud the textures of chondritic meteorites vary grcatly in their forms. Some are drop-shaped. but others are highly irregular. Most are composed chiefly of olivine and pyroxene (Mg. Fe, $\mathrm{Si}, \mathrm{O}$ minerals) but a lesser number are enriched in $\mathrm{Ca}, \mathrm{Al}$, and (in some cases) $\mathrm{Na}$. The present paper will consider only the first and most populous category, the $\mathrm{Mg}$, Fe-rich chondrules.

Six categories of $\mathrm{Mg}$, Fe-rich chondrules are delineated in Table I; examples are shown in Figure 1. Other variants are present in the chondrites, but the great majority of chondrules can be placed in one of these classes. It can be argued that several different processes probahly gave $r i s e$ to these objects, and not all of them should be called chondrules. This is an important philosophical

TABLE I

Principal classes of $\mathrm{Mg}$, Fe-rich Chondrules in Prinitive (relatively unmetamorphosed) Chondrites.

\begin{tabular}{|c|c|c|c|c|}
\hline Class & Physical Character & $\begin{array}{l}\text { Metal } \\
\text { (troilite, magnetite) }\end{array}$ & $\begin{array}{l}\text { Composition } \\
\text { of olivine } \\
\text { pyroxene }\end{array}$ & $\begin{array}{l}\text { Principal } \\
\text { Occurrence }\end{array}$ \\
\hline 1 & $\begin{array}{l}\text { Porous aggregations } \\
\text { of mafic minerals, } \\
\text { matrix material } \\
\text { fills pores }\end{array}$ & $\begin{array}{l}\text { Sparse; as inclusions } \\
\text { in mafic minerals }\end{array}$ & $\mathrm{Fe}^{++}$-poor & $\mathrm{C} 2$ \\
\hline 2 & $\begin{array}{l}\text { Highly irregular, } \\
\text { hut compact (few } \\
\text { or no voids) }\end{array}$ & $\begin{array}{l}\text { Present; evenly dis- } \\
\text { persed }\end{array}$ & $\mathrm{Fe}^{++}-$poor & $\mathrm{C} 2, \mathrm{C}, 3$ \\
\hline 3 & $\begin{array}{l}\text { Irregular, but more } \\
\text { rounded than (2) }\end{array}$ & $\begin{array}{l}\text { Present in chondrules, } \\
\text { concentrated near the } \\
\text { surface }\end{array}$ & $\begin{array}{l}\text { Variable } \\
\mathrm{Fe}^{++} \text {content }\end{array}$ & $\mathrm{t}^{\mathrm{C} 2, \mathrm{C}, 3}$ \\
\hline 4 & Roughly rounded & $\begin{array}{l}\text { Present in chondrules, } \\
\text { concentrated near the } \\
\text { surface }\end{array}$ & $\begin{array}{l}\text { Variable } \\
\mathrm{Fe}^{++} \text {content }\end{array}$ & $\mathrm{C} 3$ \\
\hline 5 & Rounded & $\begin{array}{l}\text { Coats outside of } \\
\text { chondrules, absent } \\
\text { inside }\end{array}$ & $\begin{array}{l}\text { Variable } \\
\mathrm{Fe}^{++} \text {content }\end{array}$ & $\begin{array}{l}\text { Unequili- } \\
\text { t hrated ordi- } \\
\text { nary chondrites }\end{array}$ \\
\hline 6 & Very well rounded & Absent & $\begin{array}{l}\text { Variable } \\
\mathrm{Fe}^{++} \text {content }\end{array}$ & $\begin{array}{l}\text { Unequili- } \\
t \text { brated ordi- } \\
\text { nary chondrites }\end{array}$ \\
\hline
\end{tabular}

question. It should be stressed that chondrules display a complete gradation of properties across the six categories of Tahle I; the houndaries drawn for the categories are quite arbitrary. Many chondrules display the properties of two categories. This gradational continuity strongly indicates that variations upon a single genetic process created the chondrules. Whether all the objects in the succession should be called chondrules is merely a semantic question. It seems essential, however, that a postulated chondrule-forming process be capahle of 
accounting for the whole range of properties of these objects, not only for the perfect droplets (class 6 ).

When examined in detail, impact melting as a mechanism of formation for chondrules seems unsatisfactory for a number of reasons. Judging from the character of the lunar regolith, impact on a planetary surface is not nearly efficient enough as a chondrule-forming process to account for the chondrites that consist largely of these objects. (The lunar regolith consists mostly of angular rock fragments and irregular masses of hubbly glass and partly-melted mineral fragments. Chondrules and glassy droplets form $<1 \%$ of typical lunar soils). Furthermore, impact melting of a reasonably homogeneous target rock cannot account for the diversity of composition of chondrules (Walter and Dodd 1972). If largescale heterogeneity of the target is postulated, then the overall uniformity of composition among the various chondrite classes cannot be rationalized. The model of Reid et al. (1974), wherein tiny impacts onto a hypothetical coarse-grained target melt out droplets dominantly from one mineral grain or another in the target, does not seem physically realistic.

Chondrule formation via mutual collisions of meteorites in the centimeter size range is difficult to reconcile with the astrophysical context. The process could not have occurred in the solar nebula, hecause gas drag would have kept the meteoroids in relatively circular, low-inclination orbits, preventing them from attaining the $>3 \mathrm{~km} / \mathrm{sec}$ relative velocities needed to form droplets by the jetting mechanism (Kieffer 1975). If the process occurred after dissipation of the nebula, on the other hand, relative velocities of the chondrules produced would be too great to permit prompt re-accretion into chondrite masses having characteristic chondrule populations. Aceretion would occur (if at all) onjy much later, after extensive mixing of chondrule types. There would be no damping influence in the solar system at this stage to reduce relative velocities to less than the high values originally needed for chondrule production, so accretion could occur (at these high velocities) only on the surfaces of relatively massive bodies. This high-velocity accretion would systematically destroy the original chondrule population, and produce a layer of hroken and partly-melted debris akin to the lunar regolith. Again, impacts hetween small meteoroids would not transform $>50^{\circ}$ of their sulstance into chondrules; as with impacts on a planetary surface, most of the dehris produced would be fragmental, and a mechanism must be postulated that sorts and concentrates chondrules (without seriously biasing the chemical composition of the enriched fraction).

Neither impact mechanism rationalizes the structure of class 3 and 4 chondrules. The concentric arrangement of metal in these objects suggests that they grew, with successive layers heing added by accretion or condensation.

The principal difficulty with condensation from a gas of solar composition as a mechanism of chondrule formation is that the field of stability of silicate liquids occurs at relatively high gas pressures in such a system (Suess 196.3). About 100 atm total gas pressure at $1800^{\circ} \mathrm{K}$ is needed to condense $\mathrm{Mg}$, Fe-rich chondrules as completely liquid droplets, and general considerations indicate that this juxtaposition of temperature and pressure did not obtain in the solar nebula. Where temperature stood at $1800^{\circ} \mathrm{K}$ in the nebula, it appears that the gas pressure would have been $<1$ atm. Podolak and Cameron (1974) suggest the atmosphere of the Jupiter protoplanet as a source of chondrules, because their modelling indicates appropriatcly high pressures and low temperatures in that regime; Blander and Katz. (1967) propose condensation as supercooled liquids because the pressure requirement for condensation falls sharply with temperature.

One other way to condense liquid silicate droplets is to relax the requirement that the composition of the cooling gas be identical to that of the sun. The less II and the more metal vapors present in the gas, the lower the pressure at which liquid silicates are stable. Suess (1963), Herndon and Suess (1976), and Herndon (this volume) have postulated the removal of $\mathrm{H}$ from the system under consideration by an unspecified mechanism. It has seemed more realistic to the 
senior author to contemplate fractionations between the gas and dust components of the nebula during the early stages of solar system history (Wood 1963, 1967). This is not quite equivalent to simple depletion of $H$, since the nebular gas component would have contained the bulk of the nebular $O$ and $C$ as well as $H$.

Wood (1963) has suggested that dust would tend to concentrate near the midplane of the nebula, and in stagnant regions between turbulent eddies. (It is, in fact, difficult to see how gas and dust could have been kept uniformly mixed during the collapse and early evolution of the nebula). It is then necessary to postulate transient high-energy events in the nebula that heated the gas and vaporized the dust. Durjng subsequent cooling, the metal vapors recondensed; in metalrich regions where dust had concentrated, chondrules were the product of recondensation. The energetic events postulated are high-pressure shock waves; this aspect of the model is discussed below.

The present paper explores the effect of different gas-dust mixing ratios on the character of the condensate that might be expected. The compositions of the gas and dust components assumed are shown in Table II. (Helium is included only

TABLE II

Compositions of Dust and lias Components Used in Condensation Calculations (normalized to $\mathrm{Si}=10^{6}$ )

\begin{tabular}{lcc} 
& Dust $^{\mathrm{a}}$ & $\mathrm{Gas}^{\mathrm{b}}$ \\
$\mathrm{H}$ & $5.9 \times 10^{6}$ & $3.2 \times 10^{10}$ \\
$\mathrm{He}$ & $7.8 \times 10^{6}$ & $1.4 \times 10^{7}$ \\
$\mathrm{C}$ & $6.9 \times 10^{5}$ & $1.1 \times 10^{7}$ \\
$\mathrm{Si}$ & $1.0 \times 10^{6}$ & $\cdots$ \\
$\mathrm{Mg}$ & $8.3 \times 10^{6}$ & $\cdots$ \\
$\mathrm{Fe}$ & $4.6 \times 10^{5}$ & $\cdots$ \\
$\mathrm{S}$ & & $\ldots$ \\
\hline
\end{tabular}

\footnotetext{
a Relative ahundances in the Orgueil Cl chondrite (Wiik, 1963).

${ }^{b}$ Solar system abundances of the elements (Cameron, 1970), minus enough "dust" (column 1) to remove all condensable elements ( $\mathrm{Si}, \mathrm{Mg}, \mathrm{Fe}, \mathrm{S}$ ).
}

for its effect on total system pressure). System compositions in which the concentration of the dust component had heen increased by $1 x, 10 x, 100 x$, and $1000 x$ were tested. For each dust concentration factor the condensation curves for crystalline olivine, troilite, and metallic iron were calculated from the thermodynamic equilibrium constants for the condensation reactions. In evaluating the condensation of $\mathrm{Fe}$ vapor to form the $\mathrm{Fe}_{2} \mathrm{SiO}_{4}$ component of olivine, reactions involving $\mathrm{CO}$ as well as $\mathrm{H}_{2} \mathrm{O}$ as an oxidant were considered. (Carbon turned out not to figure importantly in the condensation reactions for any of the dust concentration factors investigated). A consideration of further reaction of olivine to form pyroxene, at lower temperatures, was omitted from this study.

Results are shown in Figure 2. The melting temperatures of FeS and meta11ic Fe are entered; representation of the liquid fields of these substances at pressures and temperatures ahove the triple point is straightforward. This is not the sase for the siijcate component of chondrules, which melts over a wide range of temperatures. The interstitial material between olivine or pyroxene crystals in 

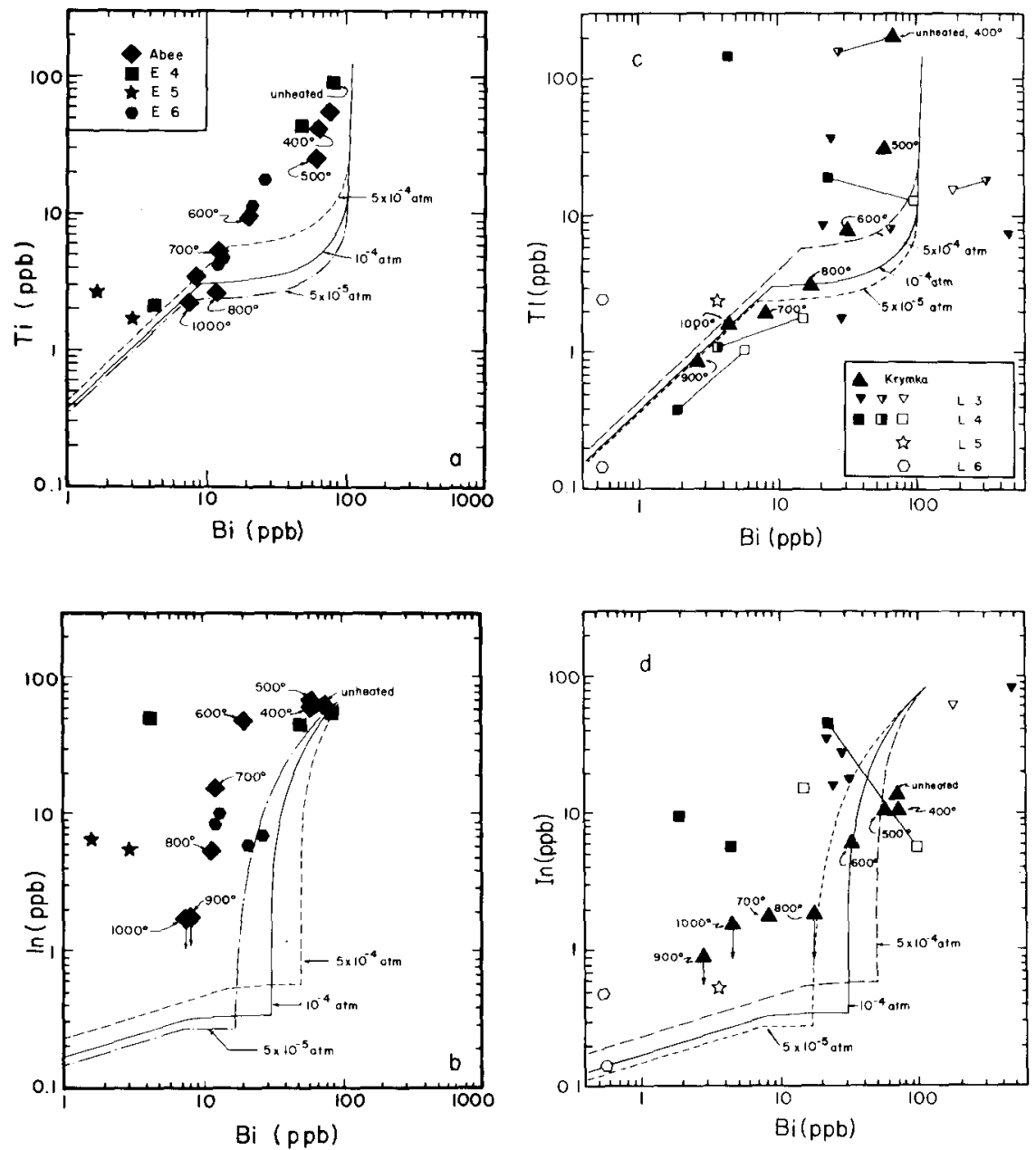

Eiqure 2. Pressure, temperature conditions at which various materials would begin to condense from a cooling vapor, for four different dust concentration factors (see text). Pr, pressure at the time of condensation. $p_{0}$. pre-shock pressure of gas. (Shock compression would increase $T$ from $273^{\circ} K$ at $P_{0}$ to the condensation temperature of olivine at $\left.P_{T}\right)$. Heavy curves: condensation of metallic fe. Light curves: condensation of olivine (numbers express mole percent of the $\mathrm{Mg}_{2} \mathrm{SiO}_{4}$ end member).

Dashed curves: reaction of Fe metal to form troilite (Fes). Hatched reqions: low $P, T$ corners of fields of stability of liquid troilite and Fe metal. Stippled regions: corners of stability fields of crystalline olivine - silicate liquid mixtures.

chondrules begins to melt at $\sim 1470^{\circ} \mathrm{K}$, but complete melting of $\mathrm{Mg}$ olivine in them does not occur until $2160^{\circ} \mathrm{K}$. The stippled zone of "liquid silicates" in Figure 2 must be considered to have extremely variable properties: at the low-temperature edge of the field, the material represented is a crystalline mush with very little liquid between the crystals; the farther one goes to the right in the stippled field, the greater is the proportion of liquid. 


\section{CHONDRULES}

The $\mathrm{Fe}^{++}$content of equilibrium olivine increases with lowering temperature, as shown by the three olivine curves entered (the numbers record the mole percent of $\mathrm{Mg}_{2} \mathrm{SiO}_{4}$, which is complementary to the content of the $\mathrm{Fe}^{++}$-bearing component, $\mathrm{Fe}_{2} \mathrm{SiO}_{4}$ ).

Four parameters are variable in the condensation situation postulated. It appears that the diversity of chondrules observed in chondrites can be understood in terms of the values of those parameters that obtained during condensation.

(1) The dust concentration factors. Increase of the dust component not only lowers the pressure needed for condensation, but it shifts the relative positions of the olivine and Fe metal condensation curves (Figure 2). If most of the $\mathrm{Fe}$ condenses as metal ahead of olivine $(l x)$, the olivine that condenses will be $\mathrm{Fe}^{++}$ poor. Equilibrium requires that some of the Fe be oxidized and transferred to olivine as temperature declines, but this may not have time to occur if cooling is rapid; the silicate component of the condensate remains $\mathrm{Fe}^{++}$-poor. If silicates condense ahead of $\mathrm{Fe}$ metal $(1000 \mathrm{x})$, they have access to all the Fe vapor in the system, and can become enriched in $\mathrm{Fe}_{2} \mathrm{SiO}_{4}$. Fe metal may be excluded from the chondrules because it does not condense until the silicate system has solidified.

(2) Gas pressure. For any given dust concentration factor, the nature of the condensate varies greatly with the pressure of the cooling nebular gas (e.g., Figure 3).

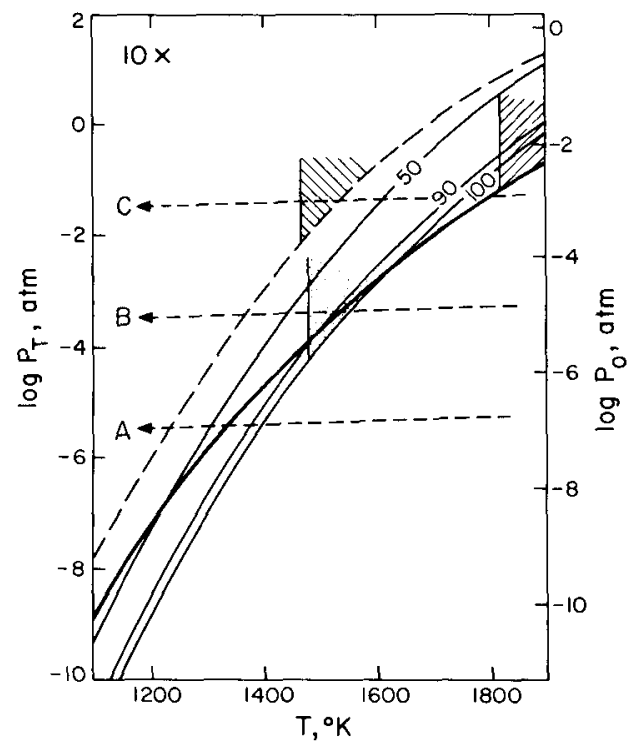

Fiqure 3. Cooling of gases at three different pressures, in the condensation diagram applicable to a system in which the dust component is enhanced by $10 x$. A: Cooling at a pressure beneath all liquid fields; solid silicate and metal dust particles condense. B: cooling through the liquid-poor corner of the silicate "liquid" field. Solid metal and olivine crustals and a small amount of siliceous liguid condense. Together these form an irregulat adhering mass. C; Solid metal condenses, monopolizing most of the $F e$ in the system. Fe+t-poor olivine and a substantial amount of liquid condense. All three components form a chondrule of substantial (momentary) fluidity, and hence roundness.

(3) Nucleation temperature. The composition of condensing material changes with temperature. The lower the temperature of chondrule nucleation, the greater its content of $\mathrm{Si}, \mathrm{Fe}^{++}, \mathrm{Na}$, and certain other elements is likely to be. 
(4) Cooling kinetics and/or the base temperature to which a local system cools. This affects the degree to which post-condensation reactions between the metal in chondrules and the gas can proceed to equilibrium. If the system cools rapidly to a low temperature, metal in the chondrules is largely preserved as such. If cooling is asymptotic to a somewhat higher temperature, extensive conversion of metal to magnetite can occur. If the chondrules cool even more slowly, metal in then may be converted largely or wholly to troilite (FeS).

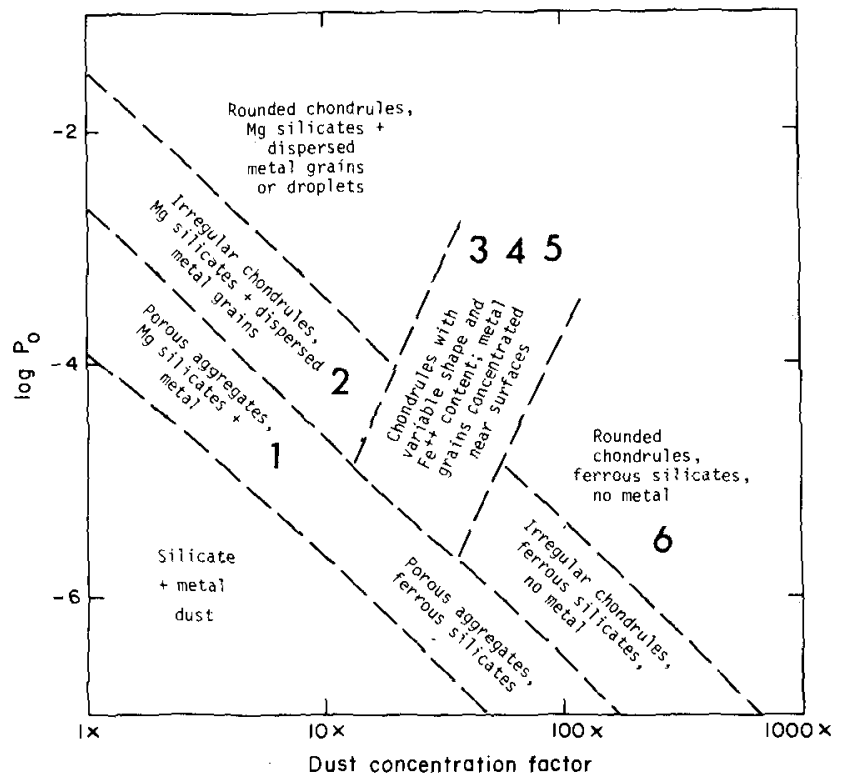

Figure 4. Map of chondrule types produced by condensation under diverse comditions of $P_{0}$ and dust concentration factor; derived by consideration of various condensation tracks as in Figure 3 . Numbers refer to chondrule classes in Table $I$.

Considering the first two of these variables to be the most important, we have attempted to map the types of condensate that would appear for different values of $P_{0}$ and the dust concentration factor (Figure 4). Most of the chondrule classes in Table I appear to have a place in this diagram. Taking account of the chondrule populations of the various chondrite types, it would appear that $\mathrm{C} 2$ chondrites formed in nebular regions where the dust concentration was $-10 x$; C. chondrites, $\sim 30 \mathrm{x}$; and unequilibrated chondrites, $\sim 100 \mathrm{x}$. Pre-shock system pressures were in the range $10^{-5}$ to $10^{-3} \mathrm{~atm}$.

(Although the model advocated produces chondrules with a high content of primary $\mathrm{Fe}^{++}$in some circumstances, it should be stressed that this does not obviate the need for chemical equilibration via diffusive transfer during subsequent thermal metamorphism of the ordinary chondrites. Though the mean content of $\mathrm{Fe}^{++}$in the chondrules postulated is high, it would also be extremely variable, just as is observed in the unequilibrated ordinary chondrites. The extreme homogeneity of mineral compositions in recrystallized ordinary chondrites could not be obtained without some post-accretional equilibration of mineral compositions).

The concept of high-energy shock waves as an important ingredient of the primordial solar system is admittedly speculative. Presumably this activity did not occur even as late as the Herbig-Haro or T-Tauri stages of pre-main sequence solar 
evolution, since the mass loss from stars in both stages (Strom et al. 1974) is vigorous enough to sweep away chondrules or dust that condensed. The postulated transient heating must have occurred during the very first and least well-understood phase of solar system formation, the infall stage. To suggest the mechanism of heating is beyond the competence of the writers; however, infall of an irregular volume of interstellar gas and dust in which density was heterogeneously distributed cannot have been a placid occurrence, and it seems unlikely to us that shock heatings of the required magnitude at that time can be ruled out conclusively.

\section{ACKNOWLENGEMENTS}

This research was supported in part by NASA Grant NSG 7132 .

\section{REFERENCES}

Blander, M., and Katz, J. L. 1967, Geochim. Cosmochim. Acta, 31, 1025.

Cameron, A.G.W. 1973, ICarus, 18, 407.

Cameron, A.G.W. 1970, Space Sci. Rev., 15, 121.

Cameron, A.G.W. 1966, Earth Planet. Sci. Letters, 1, 93.

Dodd, R. T, 1971, Contrib. Mineral. Petrol. 31, 201.

Fredriksson, K., Noonan, A., and Nelen, J. 1973, The Moon, 7, 475.

Herndon, J. M., and Suess, H. E. 1976, Can the Ordinary Chondrites have Condensed from a Gas Phase? (Preprint).

Kieffer, S. W. 1975, Science, 189, 333.

King, E. A., Carman, M. F., and Butler, J. C. 1972, science, 175, 59.

Kurat, G. 1967, Geochim. Cosmochim. Acta, 31, 491.

Lange, D. E., and Larimer, J. W. 1975, Science, 182, 290.

Podolak, M., and Cameron, A.G.W. 1974, Icarus, 23, 326.

Reid, A. M., Williams, R. J., Gibson, E. K., and Fredriksson, K. 1974, Meteoritics, 9,35 .

Strom, S. E., Grasdalen, G. L., and Strom, K. M. 1974, Astrophys. J., 191, 111.

Suess, H. E. 1963, in R. Jastrow and A.G.W. Cameron (eds.), origin of the Solar System, Academic Press, New York, p. 143.

Suess, H. E. 1949, Z. Elektrochem. 53, 237.

Urey, H. C. 1967, Icarus, 7, 350 .

Walter, L. S., and Dodd, R. T. 1972, Meteoritics, 7, 341.

Wasson, J. T. 1972, Rev. Geophys. Space Phys. 10, 711.

Whipple, F. L. 1972, in A. Elvius (ed.), Nobel Symposium No. 21: from Plasma to Planet, Almqvist and Wiksell, Stockholm, p. 211.

Whipple, F. L. 1966, Science, 153, 54.

Wiik, H. B. 1963, Space Sci. Rev. 1, 621.

Wlotzka, G. 1969, in P. Millman (ed.), Meteorite Research, D. Reidel, Dordrecht, p. 174 .

wood, J. A. 1967, Geochim. Cosmochim. Acta, 31, 2095.

Wood, J. A. 1963, Icarus, 2, 152.

Wood, J. A. 1962, Geochim. Cosmochim. Acta, 26, 739. 